\title{
Novel Strategies of Immunization against COVID-19
}

\author{
Aparajita Sen $^{1}(\mathbb{D})$, Sunita Aggarwal ${ }^{2 *}$ (D) Shalini Sehgal ${ }^{3}(\mathbb{D})$ Nitika Nagpal $^{2}(\mathbb{D}$,

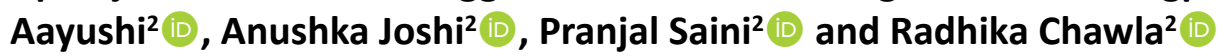 \\ ${ }^{1}$ Department of Genetics, University of Delhi South Campus, New Delhi - 110 021, India. \\ ${ }^{2}$ Department of Microbiology, Institute of Home Economics, University of Delhi, New Delhi - 110 016, India. \\ ${ }^{3}$ Department of Food Technology, Bhaskaracharya, College of Applied Sciences, \\ University of Delhi, New Delhi - 110 075, India.
}

\begin{abstract}
COVID-19 manifested itself as a global pandemic in 2019 but even in 2021, it is still not successfully contained. This virus has claimed millions of lives worldwide and rendered many more jobless. Apart from causing mild to severe pneumonia, the virus has also caused a loss of livelihood for thousands globally, along with widespread trauma and depression. Since the transmission rate of the virus is so high, temporary prophylaxis relied on sanitization, wearing masks and physical distancing. However, a long-term solution for stopping viral spread is vaccination. Apart from being the fastest way to induce immunity against the virus, vaccination is also the cheapest and most practical way. However, a vaccine can only be commercially available after it has passed through various clinical trial phases. So far, more than two hundred potential vaccine candidates underwent different phases of the clinical trial, and some of the front-runners have shown more than $90 \%$ efficacy. This review has compiled all such vaccine candidates, their types, their modes of action, and the associated pros and cons. The current advances in clinical trials of vaccines have also been discussed, such as plant-based and cocktail vaccines that have recently emerged. Nowadays, novel strains like Delta plus are also emerging and posing a threat. Thus, it is mandatory to get vaccinated and choose a vaccine that provides long-term protection against multiple strains.
\end{abstract}

Keywords: COVID-19, Vaccine, Pandemic, Pfizer-BioNTech, SARS-Coronavirus-2, Coronavirus

\footnotetext{
*Correspondence: sunita.aggarwal@ihe.du.ac.in; +91 9810220596

(Received: April 14, 2021; accepted: January 5, 2022)

Citation: Sen A, Aggarwal S, Sehgal S, et al. Novel Strategies of Immunization against COVID-19. J Pure Appl Microbiol. 2022;16(1):35-49. doi: 10.22207/JPAM.16.1.37

(C) The Author(s) 2022. Open Access. This article is distributed under the terms of the Creative Commons Attribution 4.0 International License which permits unrestricted use, sharing, distribution, and reproduction in any medium, provided you give appropriate credit to the original author(s) and the source, provide a link to the Creative Commons license, and indicate if changes were made.
} 


\section{INTRODUCTION}

The COVID-19 pandemic was an unexpected catastrophe, which claimed millions of lives worldwide. ${ }^{1}$ The disease causes severe pneumonia-like symptoms, which may also result in complications involving other organs, such as the kidneys and the brain. To restrict the damage of COVID-19, primary measures focused on quarantining and detention, with social and physical distancing, and many additional methods like constant sanitization to prevent the disease. It is essential to first understand the virus's biological mechanisms and the ability to propagate. It is known that the viral infection occurs on binding of surface spike (S) proteins to the AngiotensinConverting Enzyme 2 (ACE2) receptors present throughout the body including lung type II alveolar cells (AT2), cells of upper throat, ileum, colon, and kidneys, cholangiocytes, myocardial cells, and bladder urothelial cells thus enable the novel coronaviruses to infect a variety of cells. ${ }^{2}$

On the basis of this understanding, precautionary plans have 3 priorities: first, good hygiene practices and social distancing; second, to increase viral monitoring, and to eventually target local viral confinement and limit spread wherever possible; and third, to increase the immunity of the global population as soon as possible. ${ }^{3}$

To avoid the spread of the pandemic, the reproduction number of the virus, Ro (an indicator of viral transmission), must remain less than 1 , which means the probability of virus transmission from every infected person is less than one to a susceptible individual. This is a major goal of successfully decreasing the number of cases. ${ }^{4}$ Activation of both innate and adaptive immunity involving $B$ cells and $T$ cells are part of the immune response against the SARS-CoV-2. ${ }^{5}$ Defense against viral infection is mainly provided by antibodies that neutralize viral antigens, a concept that is applied to the majority of viral infections, wherein prophylaxis relies on vaccination. ${ }^{6}$ It is thus required to immediately develop vaccines that aim at bringing about protective immune responses, mainly via antibodies that will be able to neutralize antigens specific to SARS-CoV. ${ }^{7}$

Although the production and availability of effective vaccines takes time, at least one to two years, vaccination is still the most economical and rapid course of action for achieving worldwide immunity. ${ }^{8}$ The possibilities of virus transmissibility will decline to only a few individuals on achieving herd immunity i.e. a significant portion of the population becomes immune to viral infection. ${ }^{9}$ Many international organizations viz. World Health Organization (WHO), the Coalition for Epidemic Preparedness Innovations (CEPI), and The Global Alliance for Vaccines and Immunizations (GAVI) are stepping up their efforts to prepare the world to face such pandemics if happens in coming years. ${ }^{10}$ Despite it requiring several years to clinically test and commercialize vaccines, the case of COVID-19 was different. The first case was reported in November 2019, and by the end of January 2022, more than 10.1 billion doses of vaccines have been administered globally. ${ }^{11}$ This global immunization was possible at such a rapid rate, because of the non-stop hard work of scientists and clinicians all over the world in tandem. However, it has been seen that one can still get CoV-2 infections even after completing the vaccination regime, but the chances of mortality and hospitalization decreased to a great extent. ${ }^{12}$ In this review, we will explore the existing candidates for vaccination and immunization against SARS-CoV-2 and analysed their target antigens and effective immunization strategies adopted.

\section{Structure of the Coronavirus}

When samples from workers in the Wuhan seafood market who were suffering from pneumonia were analyzed, it was observed that the new coronavirus, SARS-CoV-2 with a genome of $29.9 \mathrm{~kb}$ in size, was responsible for the disease. Structurally, the virus consists of four major proteins, i.e., the spike (S), membrane (M), envelope ( $\mathrm{E}$ ) and nucleocapsid (N) along with many other proteins. ${ }^{13}$

$\mathrm{S}$-glycoprotein is a transmembrane homotrimer on the surface of the virus and these facilitate virus binding to lower respiratory tract cells through angiotensin-converting enzyme 2 (ACE2) receptors on the cell surface. Furin-like host proteases cleave the S glycoprotein into S1 and S2 subunits. $S 1$ regulates the affinity of the virus to cell type, while $\mathrm{S} 2$ is involved in viral fusion with host cells. ${ }^{14}$

The structure and function of $S$ glycoprotein of this newly discovered coronavirus SARS-CoV-2 are not like other highly contagious 
beta coronaviruses, such as Middle East Respiratory Syndrome Coronavirus (MERS-CoV) and Severe Acute Respiratory Syndrome Coronavirus (SARSCoV) encountered earlier in the century. S1 comprises of a receptor-binding domain (RBD), which binds with cellular ACE2 receptors while S2 forms a hexagonal bundle nucleus on fusion of cell and virus membranes. ${ }^{15}$ By targeting these spike proteins (S glycoprotein) infection by SARSCoV-2 can be prevented. It is thus necessary to create neutralizing antibodies that target these proteins namely, S1 RBD, S1 N-terminal domain, or S2 region for protection against SARS-CoV-2 infection. These antibodies on interacting with RBD moiety of S1 or with S2 proteins block the binding and entry of virus to the host cell, and thus stopping infection. ${ }^{16} \mathrm{Hindering}$ binding fusion steps reduces virus uptake and reproduction, and most vaccine candidates thus, target $\mathrm{S}$ glycoprotein as the primary antigen. ${ }^{17}$

Some of the potential candidate vaccines against the novel Coronavirus have been listed in the following sections, as well as in Fig. 1.

\section{Non-Replicating Viral Vectors}

These are the most promising options for COVID-19 prevention as these elicit strong antibody and cell-mediated immunity that offers protection after just one or two doses. They cannot multiply within the host cells, yet they are adequate to elicit host immune responses and necessary long-term protective immunity, unlike inactivated or subunit vaccines, which only induce immunity for a certain period of time and require booster doses. ${ }^{18}$

The target pathogen is inactivated using heat or chemical (formalin) treatments, which render the pathogen replication-defective while leaving it intact and allowing the human immune system to recognize it and respond accordingly. ${ }^{19}$ Due to lack of replicating capacity, this form of vaccination is safer, as viral reversion is not a concern. Furthermore, they stimulate both CD8+ $T$ cells and antibody-mediated immune responses, thus lowering the risk of antigen-induced illness. ${ }^{20}$

Adenovirus type 5 is one of the commonly used viral vectors used in vaccine production.

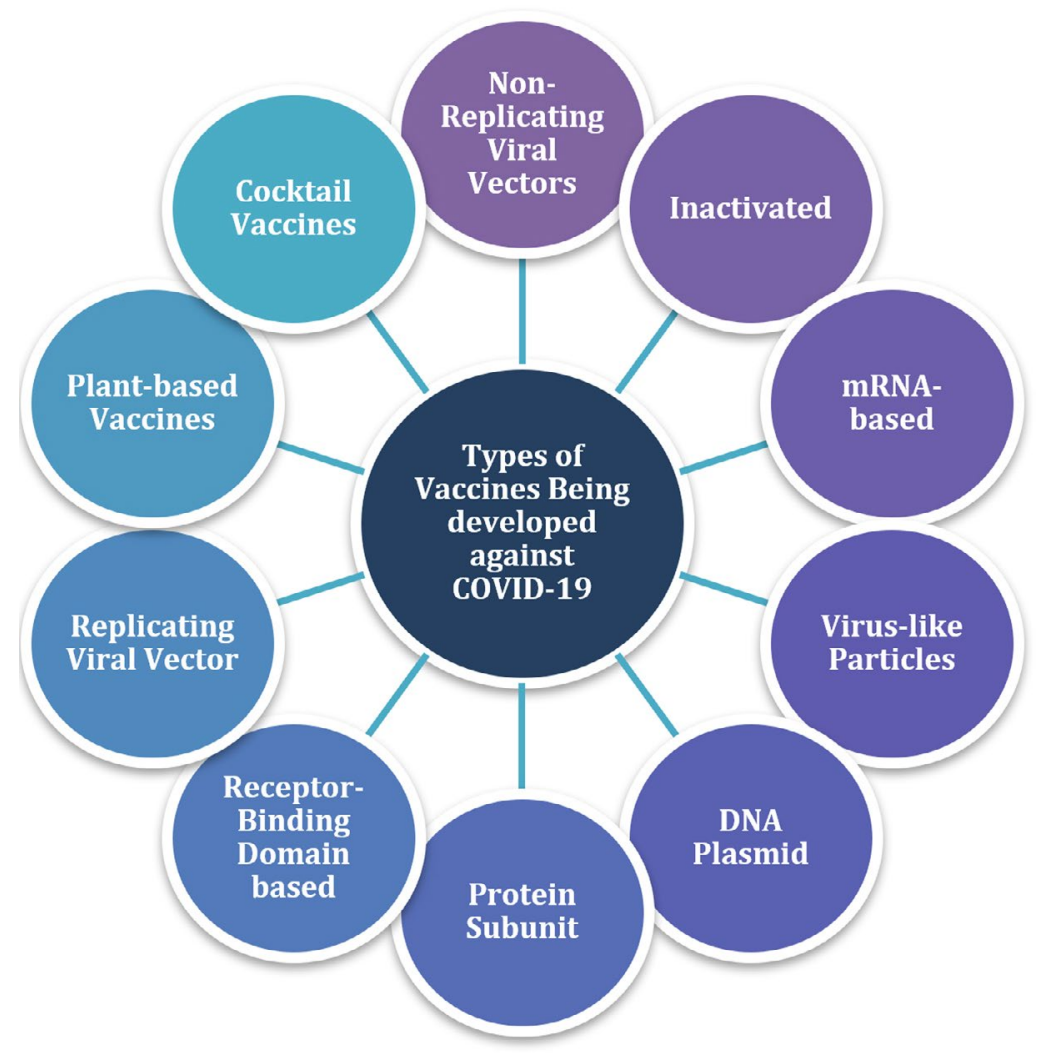

Fig. 1. Candidate vaccines for Immunization against COVID-19 
A cassette that produces a foreign therapeutic gene replaces some essential viral genes. ${ }^{7}$ Ads (Adenoviral Vectors) are known to be highly immunogenic, making them ideal to be used as vectors in gene therapy and vaccine delivery.

Advantages like ability to generate antibody as well as cell-mediated immune responses, capacity to generate high titers in vitro, increased expression of transgenes, physical and genetic stability, availability of numerous serotypes and chimeric forms, and lack of integration into the host genome have led to the acceptance of these vaccines. Immune responses elicited by vector-based vaccinations should target both the antigen and the vector component. As a result, heterologous vaccination is the ideal vaccination strategy, as it mitigates any unfavorable effects of an immune response to vector components. ${ }^{20}$

Many epidemiological studies reported the presence of anti-Ad5 neutralizing antibodies in most of the North Americans, and about $33.3 \%$ of the population has relatively high titers (>200). A similar high anti-Ad5 antibodies titer is also exhibited by people from other parts of the world. ${ }^{21}$

Pre-existing immunity or vector immunogenicity are the major disadvantages of adenovirus type 5 vectors. These could result in the dampening of responses by these vaccines. So, there is a need to develop adenoviral vectors based on alternate adenovirus serotypes. ${ }^{22}$ Generally, those serotypes are taken which are less prevalent than adenovirus serotypes 2 and 5 . For instance, a heterologous vaccine ( $r$ Ad26-S and rAd5-S) comprising of two recombinant adenoviruses- type 26 (rAd26) and type 5 (rAd5) vectors- are also being used containing gene for spike glycoprotein of SARS-CoV-2 virus. ${ }^{23}$

In general, the vaccine stimulates dendritic cells, causing efficient antigen presentation, upregulation of release of cytokines, chemokine and evoking co-stimulatory signals to the $B$ and $T$ cells and producing powerful immune responses. ${ }^{24}$ Because they primarily target epithelial cells, Ad vectors are the most attractive options for eliciting both systemic and mucosal immune responses.

Adenovirus vectors have also been used widely for vaccine development against HIV and numerous other DNA, single and double-stranded
RNA viruses. A total of 57 human adenoviruses have been discovered and classified into seven different species (A-G). Adenovirus receptors are present on the surface of most human cells, allowing the virus to infect a wide range of tissues. ${ }^{25}$ The transgenic expression cassette (antigen inserted from the target pathogen) replaces two early adenovirus genes, E1A and E1B, preventing the virus from replicating within the host cell. Furthermore, the deletion of the E3 and $\mathrm{E} 4$ genes in viral vectors protects adenovirusinfected cells from being killed by the host cell and provides transgenic stability. ${ }^{26}$ CanSino vaccine, developed by the Beijing Institute of Biotechnology, is based on the non-replicating viral vector method described above using Adenovirus type $5 .{ }^{27}$ Based on data from certain studies, this vaccine has a 65.7 percent chance of avoiding symptoms, making it a strong contender for the battle against COVID-19. ${ }^{28}$

Gameleya Institute, Russia prepared the first Coronavirus vaccine to be registered, that is Sputnik V, which works on the above discussed mechanism of non-replicating viral vector, with heterologous type 26 and type 5 as vectors. The use of two different serotypes, that are given 21 days apart, is supposed to triumph over any pre-current adenovirus immunity within the population. Sputnik $V$ has shown an efficacy of 91.6 percent in phase 3 clinical trials. This vaccine can be stored at +2 degrees to +8 degrees, giving an upper edge over mRNA vaccines, which require high-temperature control of $-70^{\circ}$ to $-20^{\circ} \mathrm{C}$ for storage. It is one of the front-runners for immunization against SARS-CoV-2. ${ }^{29}$

Johnson \& Johnson's and AstraZeneca's monologue vector type 26 vaccines are both based on the same non-replicating viral vector mechanism..$^{30}$ The AZD1222 vaccine against COVID-19 has an effectiveness of 63.09 percent, but may give rise to a symptomatic SARS-CoV-2 infection. Longer gaps of 8-12 weeks between multiple doses have been linked to increased effectiveness of vaccination. ${ }^{31}$ The goal of Reithera/ LEUKOCARE/ Univercells is to create a SARS CoV2 vaccine utilizing vectors derived from GRAd, a replication-defective simian adenoviral vector, which may be used instead of human adenovirus type 5 vaccine vectors. ${ }^{32}$ 


\section{Inactivated Vaccines}

In these vaccines, heat or chemicals destroy the pathogen before being delivered to the body. Even after it has been destroyed, the virus retains its capacity to serve as an immunogen. The immune system stays completely functional when such a virus is introduced into a host. ${ }^{33}$

These vaccines contain epitopes, which are identical to those that a virus would display if it infected the host cell, thus eliciting an immune response. The existence of antibodies against at least eight distinct viral proteins was discovered when sera from COVID-19 patients were tested, indicating the presence of several additional antigens on the pathogen's surface that may be targeted for protective antibody formation. ${ }^{34}$ Additional structural proteins coding for the envelope (E), spikes (S), and matrix (M) were discovered to have immunogenicity. ${ }^{35}$

Sinovac Biotech, Institute of Medical Biology, and Research Institute for Biological Safety Problems are attempting to develop a fully inactivated viral particle vaccine with alum as an adjuvant. This worked against the SARS virus. Inactivated vaccines can be manufactured on a mass scale easily by many countries, making them beneficial in the fight against SARS-CoV2. ${ }^{27}$ CoronaVac has shown excellent immunogenicity in mice, rats, and non-human primates, with production of vaccine-induced neutralizing antibodies against SARS-CoV-2, indicating that it is a potent candidate for the COVID-19 vaccine. ${ }^{36}$

The viral structure remains intact in the whole virion inactivated vaccines after inactivation so that the immune system can recognize it. While developing this vaccine, the virions were left intact. This makes them less virulent, while retaining their capacity to serve as immunogens. In the course of their activity, these vaccines reveal specific epitopes (which a live virus would have shown otherwise) that elicit an immune response. Further research has been done to find other structural proteins that protective antibodies target, and it has been discovered that envelope (E), spike $(\mathrm{S})$, and matrix (M) proteins are being targeted. Protective antibodies can have multiple targets. ${ }^{37}$

These vaccines result in the activation of immune cells and generation of memory cells, which detect \& destroy rapidly on encountering virulent viruses, thus preventing the infection from spreading and multiplying. ${ }^{38}$ This method is being used by Bharat Biotech to produce Covaxin. ${ }^{39}$ Covaxin stimulates an immunological response by introducing pathogens that have lost the ability to reproduce, while still retaining the antigenic proteins capable of activating the immune cells. The data gathered so far shows both a robust in vivo immune response (antibody and T cell) and also in-vitro viral neutralization with around 93.4 percent efficacy against severe symptomatic infections. ${ }^{40}$

\section{mRNA Based Vaccines}

mRNA based vaccines elicit a strong immunological response, that includes both cellular and humoral immunity without being subjected to MHC haplotypic limitation. It provides excellent safety and a lot of flexibility in terms of manufacturing and use. As physicochemical properties of mRNA mostly remain unaltered even on changing the encoded protein and thus the sequence of the RNA molecule, a wide range of products may be made using the same standard production method, resulting in cost and time savings compared to alternative vaccination platforms. Furthermore, because mRNA is a small, transient vector of information that makes no attempt to get incorporated into the recipient's genome, it is an intrinsically safe vector. mRNA vaccines are also preferred as expression of any protein is possible without requiring any modification of the manufacturing process. ${ }^{41}$ Altogether, mRNA proves to be a favorable vector that may become the foundation for a breakthrough platform for vaccine technologies. Once the vector enters the cell, self-amplification RNA (saRNA) replicates itself, and instructs the cell's own machinery to produce the glycoprotein of the Coronavirus. ${ }^{6}$ The process takes place in the cell's cytoplasm and therefore does not affect or change the cell's own genetic material. Only the spike glycoproteins are expressed on the surface of cells. Antibodies against the marker protein are produced by the immune system and play an essential role in viral control by binding to spike proteins and blocking the virus from infecting cells. This also results in long-term memory. ${ }^{42}$

This method is used in CUREVAC and the People's Liberation Army (PLA) Academy of Military Sciences/Walvax Biotech vaccines. ${ }^{43}$ In Phase I, CVnCoV was found to elicit strong humoral 
and cell-mediated immunity by all the dosages tested. Furthermore, the immunological response was similar in people vaccinated with $\mathrm{CVnCoV}$ - and those recovered from COVID-19. ${ }^{44} \mathrm{An}$ alphavirus 6 genome is used to make LNP-nCoVsaRNA. Selfamplified RNA does the coding (saRNA). After RNA is delivered to the cytoplasm, it replicates using an enzyme replicase from the alphavirus. Lipid nanoparticles (LNP), which encapsulate saRNA, are useful for developing vaccines to combat a global pandemic, since they may encode 7-9 antigens of interest even at low doses..$^{45}$ They produce a large number of Th-1-predisposed antibodies that binds SARS-CoV-2 antigens. IgG is linked to virus neutralization, cytokine production, and cellular responses to the LNP-nCOV saRNA-02 vaccine. ${ }^{20}$

Both the Pfizer-BioNTech and the Moderna COVID-19 vaccines are mRNA-based vaccines. The two showed more than 90 percent efficacy in clinical trials and got their Emergency Use Authorization (EUA) from the U.S. Food and Drug Administration (FDA) in December 2020.

\section{Virus-Like Particles (VLPs)}

VLPs structurally imitate the original viruses, allowing the body to recognize them and elicit cell-mediated as well as humoral responses. They are derived from viral antigens that are selfassembled and lack the viral genome, thus giving rise to secure and affordable vaccine candidates. ${ }^{46}$ These have led to a leading vaccine platform because of their safety, immunogenicity, and manufacturing ease. The particle characteristics and high-density presentation of proteins with a viral structure on their surface make VLPs attractive carriers of foreign epitopes. ${ }^{47} \mathrm{As}$ a result, many VLP-based vaccines have achieved significant clinical success and have been licensed for human use. The major challenge, however, is to develop new production platforms capable of delivering VLP-based vaccines while dramatically reducing production time and cost. Nowadays, plants are also used as expression systems. The advantages of this are the ability to introduce characteristic modifications after translation, cost-effectiveness, speed of production, and scalability. ${ }^{48}$

Medicago provides the CoVLP candidate vaccine along with two adjuvants, Dynanvax's CpG 1018 and GlaxoSmithKline's patented pandemic adjuvant technology. In order to increase the production of antibodies and inducing long-lasting immunity, adjuvants are added to a vaccine to strengthen the immune response, thus reducing the required antigen dose. ${ }^{46}$

\section{DNA Plasmid Vaccine}

DNA vaccines employ injection of naked recombinant plasmids having the sequence of DNA that codes for the antigen against which an immune response is sought, thus stimulating the production of antibodies. The recombinant plasmid can be administered intradermally or intramuscularly and even orally.

Plasmid vectors consist of an expression unit for expressing a transgene, and a production unit that functions as the framework of the plasmid. Their composition includes a viral promoter gene, a bacterial origin of replication, a multiple cloning site (MCS) where the transgene is inserted and an antibiotic resistance gene. ${ }^{49}$ Promoter or enhancer sequences present in expression units are generally of viral origin and regulate antigen expression in various target tissues. There is also a termination polyadenylation (poly- $A$ ) sequence, which stabilizes the translation of mRNA. ${ }^{50}$ In a study, the vaccine produced neutralizing antibodies that prevented the spike (S) protein of SARS-CoV-2 from binding the ACE-2 receptors on host cell surfaces ${ }^{51}$ Cadila Healthcare Limited is using this approach to build a vaccine against SARS-COV2. ${ }^{52}$

\section{Protein Subunit Vaccine}

Protein subunit vaccines are composed of viral surface protein or glycoprotein components that act as antigens, and have the capability to produce a protective immune response. Conventional biochemical or recombinant DNA technologies may be employed to produce these vaccines. Recombinant subunit vaccines efficiently induce cell-mediated as well as humoral responses. The risk factor involved in handling the virus is minimal. The only negative aspect associated with these vaccines is their high cost and requirement for adjuvants to elicit a vigorous immune response. ${ }^{53}$

$S$ protein plays the major role in binding with host receptors. It is thus an ideal target for antiviral medicines and vaccine development. Antibodies that inhibit viral entry can be induced by $S$ protein-based vaccinations. A study demonstrates that SARS-COV is highly infective and may be successfully countered by human 
monoclonal antibodies (mAb) that bind to $S$ protein via $\mathrm{N}$-terminal, limiting the formation of syncytia and therefore blocking receptor binding. ${ }^{54}$ However, the $S$ protein contains a few epitopes capable of triggering immunological responses that might be harmful to the host. Due to this very reason, during vaccine production, the distinguishing and eradication of these epitopes of the $S$ protein becomes mandatory. ${ }^{55}$ Sanofi Pasteur, Clover Biopharmaceutical Inc., GSK, Dynavax and Kentucky Bioprocessing Inc. are using this approach for the development of vaccines. ${ }^{20,55,56}$

Receptor Binding Domain (RBD) based vaccines are developed using antibodies particularly against the RBD of S protein. ${ }^{57}$ Novavax or NVX-CoV2373 (Combination of recombinant spike protein $(5 \mu \mathrm{g})$ with Matrix-M1 adjuvant (50 $\mu \mathrm{g})$ ) had high immunogenicity when tested on animal models, producing antibodies against the spike protein, antibodies capable of blocking the attachment of viral spike proteins to the ACE-2 receptors, and antibodies neutralizing the wild type virus. After a single dose of immunization, production of high levels of antibodies and immune cells were observed against the COVID-19 virus in clinical and lab trials that blocked the antigen-receptor binding. The efficacy was reported to be around $91 \%$ against symptomatic COVID-19 infections. Micro-neutralization titers after a single dose were high and were increased eight fold after a second dose..$^{58}$

Institute of Microbiology, Chinese Academy of Sciences and Anhui Zhifei Longcom Biopharmaceutical show that the CoV Spike RBD can be impaired by limited immunogenicity, yet it is an attractive target for vaccine development. Receptor docking is a function of the $\mathrm{S}$ protein RBD. ${ }^{59}$ Biological E Limited, an Indian company, has developed a subunit vaccine candidate, which possesses the SARS-CoV-2 Spike Protein RBD. It comes in three dosages and is combined with CpG 1018 and an alum adjuvant. ${ }^{56}$

\section{Replicating Viral Vector Vaccine}

This vaccination method uses early priming using a replicating vector. It can elicit an innate immune response, target mucosal inductive sites, and stimulate humoral as well as cellular and systemic responses. These vaccines essentially induce lifelong protective immunity. ${ }^{6}$ Security is the major factor to be looked upon while developing a vaccine. Concerns arise with the risk of disease evocation in immunocompromised individuals who have been vaccinated, and thus the vaccine virus may also spread in the population. ${ }^{60}$ The ideal SARS vaccine should generate long-term immunity after a single injection, be inexpensive to produce, and be scaled up to millions of doses. Live attenuated vaccines are particularly well suited to mass immunization because they are inexpensive to produce and promote high viral resistance. Also, a single dose can induce long-term memory. ${ }^{61}$

Measles-Vector (MV) based vaccine is one of the most effective and secure vaccines for humans, composed of an attenuated singlestranded RNA virus having negative-sense RNA. Manufacturing $M V$ vaccines on a large scale in many countries, as well as their low-cost distribution, is carried out under the instructions and supervision of the Extended Program on Immunization (EPI). It provides lifetime protection against measles with just one or two injections. The MV vector could induce sustained production of numerous HIV and flavivirus proteins, as well as strong neutralizing antibodies specific for the transgene and cellular immunological responses, even when pre-existing immunity against MV was present. The MERS-CoV S protein in the MVbased MERS vaccine could generate robust cellmediated and humoral responses. As a result of this discovery, and because the current virus also elicits antibodies that neutralize the $S$ protein, researchers altered antigen expression by inserting the gene encoding the S protein of SARS-CoV- 2 into the genome of MV. ${ }^{62}$

This method is being used for vaccine development by the Pasteur Institute, Merck Sharp \& Dohme, Themis, and the University of Pittsburgh CVR. ${ }^{63} \mathrm{An}$ efficiency rate of $90 \%$ is estimated after one dose, and $100 \%$ after complete vaccination with two doses. This vaccine stimulates longlasting B-cell and T-cell memory, essential for providing a long-term immunity.

In Intranasal flu based RBD vaccines Influenza virus is being used by Xiamen University and Beijing Wantai Biological Pharmacy as one of the viable platforms for vaccine development. Influenza vaccines are made up of attenuated influenza strains. The well-established influenza vaccine reverses genetic mechanisms and aid 
in the integration of foreign genes into the viral genome. Intranasal administration of influenza virus elicits a mucosal immune response. These reactions occur in the mucosal surfaces far from the vaccination site, which may be relevant for fighting SARS-CoV-2. ${ }^{64}$ Finally, the infrastructure to mass-produce influenza viruses for use in vaccines is now in place. The RBD of $S$ protein is the target antigen candidate of most potent neutralizing antibodies, and is used for most vaccines against SARS-CoV2. RBD is also short (200 amino acids) and folds independently, making it a promising candidate for SARS-CoV-2 protein subunit immunization. The main drawback is that previously existing immunity against the vaccination vector (influenza virus in this case) might diminish vaccine efficacy. ${ }^{65}$

\section{Plant-Based COVID-19 Vaccines}

Plants have been used to produce edible vaccines through genetic engineering before COVID-19. In the past, subunit vaccines against seasonal strains of the influenza virus were transiently expressed in tobacco plants. ${ }^{66}$ Similarly, for SARS, tomato plants had been used. ${ }^{67}$

Kentucky BioProcessing Company in the United States has created a SARS-CoV-2 subunit vaccine by producing viral nucleocapsid proteins in tobacco. Apart from subunit vaccines, plants can also produce VLP's. Immune complexes and multiepitopic vaccines can also be produced by exploiting plants. Moreover, polypeptide fusions have also been made from tobacco, thus showing the potential of developing COVID-19 vaccines using plant bioengineering. ${ }^{68}$ Some such vaccine candidates have been summarized in Table 1 .

Table 1. Plant-based vaccine candidates

\begin{tabular}{lll}
\hline Manufacturer & Type of Vaccine & References \\
\hline Kentucky BioProcessing Company, USA & $\begin{array}{l}\text { Subunit vaccine with S1 protein } \\
\text { expressed in tobacco } \\
\text { VLP-based vaccines in tobacco }\end{array}$ & {$[69]$} \\
Medicago Inc., Canada & VLP-based vaccine in tobacco \\
iBio, USA & $\begin{array}{l}\text { Genome sequence of tobacco } \\
\text { being used to develop vaccine candidates } \\
\text { Queensland University of Technology }\end{array}$ & {$[71]$} \\
University of California San Diego & $\begin{array}{l}\text { Combination of advanced manufacturing } \\
\text { strategies and molecular farming in tobacco } \\
\text { Subunit vaccine (RBD-Fc + adjuvant) }\end{array}$ & {$[73]$} \\
Baiya Phytopharm/Chula Vaccine & & {$[74]$} \\
Research Center & & \\
\hline
\end{tabular}

The manufacturing procedure starts from expression of the viral surface protein in a vector (plasmid or chimeric plant virus), and introducing it into a host plant, such as tobacco, potato and turnips, whose edible parts can be eaten by humans, resulting in oral administration of the vaccine. Injectables can also be made using techniques like electroporation, biolistics and Agrobacterium-mediated transformation. ${ }^{75}$

The advantages of having plant-based vaccines are that they are safe and economical while being effective. They can be rapidly produced and upscaled without having major side effects or requiring cold storage. However, dosage inconsistency remains an issue with plant-based vaccines. $^{75}$

\section{Cocktail Vaccines for COVID-19}

Recently, vaccine cocktails containing a mixed proportion of antibodies have been seen to be useful on the administration to patients infected by COVID-19, especially for those above 12 years and weigh more than 40 kilograms, have mild to moderate disease, and have the risk of developing severe disease without the requirement of external oxygen supply. ${ }^{76}$

A joint venture by Roche India and Cipla Limited resulted in the development of a monoclonal antibody cocktail comprising of Casirivimab and Imdevimab in equal proportions. This antibody cocktail though expensive claims to decrease the possibility of hospitalization and fatality by $80 \%$ and was suggested for individuals 
Table 2. Summary of available vaccine candidates against COVID-19

\begin{tabular}{|c|c|c|c|}
\hline Platform & Vaccine Manufacturer & Type of candidate Vaccine & Advantages and Disadvantages \\
\hline $\begin{array}{l}\text { Protein } \\
\text { Subunit }\end{array}$ & $\begin{array}{l}\text { Institute of Microbiology, } \\
\text { Chinese Academy of Sciences/ } \\
\text { Anhui Zhifei Longcom } \\
\text { Biopharmaceutical } \\
\text { Instituto Finlay de } \\
\text { Vacunas, Cuba } \\
\text { West China Hospital, } \\
\text { Sichuan University RBD } \\
\text { Clover Biopharmaceuticals / } \\
\text { GSK / Dynavax } \\
\text { Vaxine Pty Ltd/ } \\
\text { Medytox } \\
\text { University of Queensland/ } \\
\text { CSL/ Seqirus } \\
\text { Medigen Vaccine Biologics } \\
\text { Corporation, NIAID / } \\
\text { Dynavax } \\
\text { Sanofi Pasteur / GSK } \\
\text { FBRI SRC VB VECTOR, } \\
\text { Rospotrebnadzor, } \\
\text { Koltsovo } \\
\text { Kentucky Bioprocessing } \\
\text { Biological E Limited }\end{array}$ & $\begin{array}{l}\text { Nanoparticle vaccine } \\
\text { containing recombinant } \\
\text { SARS CoV-2 glycoprotein } \\
\text { with Matrix M as adjuvant } \\
\text { Adjuvanted recombinant } \\
\text { protein (RBD-Dimer) } \\
\text { RBD + Adjuvant } \\
\text { RBD (baculovirus production } \\
\text { expressed in Sf9 cells) } \\
\text { Native like Trimeric } \\
\text { subunit Spike Protein } \\
\text { vaccine } \\
\text { Recombinant spike protein } \\
\text { with Advax adjuvant } \\
\text { Molecular clamp stabilized } \\
\text { Spike protein with MF59 } \\
\text { adjuvant } \\
\text { S-2P protein + CpG } 1018\end{array}$ & $\begin{array}{l}\text { Advantages } \\
\text { - People with weakened immune } \\
\text { systems can be injected. } \\
\text { - Provides long lasting immunity. } \\
\text { - Only parts of the virus are used } \\
\text { for these vaccines therefore these } \\
\text { vaccines are considered safe. } \\
\text { Disadvantages } \\
\text { - These vaccines have to be } \\
\text { used with good adjuvant due } \\
\text { to their low immunogenicity. } \\
\text { - For long term immunity } \\
\text { multiple dosages are required. }\end{array}$ \\
\hline $\begin{array}{l}\text { Non - } \\
\text { Replicating } \\
\text { Viral Vector }\end{array}$ & $\begin{array}{l}\text { AstraZeneca / University } \\
\text { of Oxford } \\
\text { CanSino Biological Inc./ } \\
\text { Beijing Institute of } \\
\text { Biotechnology } \\
\text { Sputnik V/ Gamaleya } \\
\text { Research Institute } \\
\text { Janssen Pharmaceutical } \\
\text { Companies } \\
\text { ReiThera / LEUKOCARE } \\
\text { / Univercells }\end{array}$ & $\begin{array}{l}\text { ChAdOx1-S } \\
\text { Adenovirus } \\
\text { Type } 5 \text { Vector } \\
\text { Adeno-based } \\
\text { (rAd26 S+rAd5-S) } \\
\text { Ad26COVS1 } \\
\text { Replication defective } \\
\text { Simian Adenovirus } \\
\text { (GRAd) encoding S }\end{array}$ & $\begin{array}{l}\text { Advantages } \\
\text { Adenoviruses are able to } \\
\text { transduce non-dividing and } \\
\text { dividing cells and also } \\
\text { ensure high levels of } \\
\text { transgene expression } \\
\text { Disadvantages } \\
\text { - Highly immunogenic. } \\
\text { - The integration of vector } \\
\text { genome into the genome } \\
\text { of the host. } \\
\text { - Transient expression } \\
\text { of transgene }\end{array}$ \\
\hline Inactivated & $\begin{array}{l}\text { Beijing Institute of } \\
\text { Biological Products/ } \\
\text { Sinopharm } \\
\text { Sinopharm / Wuhan Institute } \\
\text { of Biological Products } \\
\text { Sinovac } \\
\text { Covaxin / Bharat Biotech and } \\
\text { Indian Council of Medical } \\
\text { Research (ICMR) - } \\
\text { National Institute of } \\
\text { Virology (NIV) } \\
\text { Research Institute of }\end{array}$ & $\begin{array}{l}\text { Inactivated } \\
\text { Inactivated } \\
\text { Inactivated } \\
\text { Whole-Virion inactivated }\end{array}$ & $\begin{array}{l}\text { Advantages } \\
\text { - Lyophilized and easy } \\
\text { storage. } \\
\text { - No mutating back into their } \\
\text { pathogenic form and does } \\
\text { not cause infectious diseases } \\
\text { even in people with } \\
\text { immunodeficiency. } \\
\text { Disadvantages } \\
\text { The virus or bacteria are dead } \\
\text { and do not replicate, thus } \\
\text { multiple doses (booster shots) }\end{array}$ \\
\hline
\end{tabular}




\begin{tabular}{|c|c|c|c|}
\hline & $\begin{array}{l}\text { Biological Safety Problems, } \\
\text { Rep of Kazakhstan }\end{array}$ & & $\begin{array}{l}\text { are often required to train the } \\
\text { body to defend itself. }\end{array}$ \\
\hline Virus like & Medicago Inc & Plant-derived VLP with & Advantages \\
\hline Particle (VLP) & & GSK or Dynavax adjuvants. & $\begin{array}{l}\text { Safe because there is no } \\
\text { chance of reversion. } \\
\text { Disadvantages } \\
\text { Develop new production } \\
\text { platforms capable of } \\
\text { delivering VLP. }\end{array}$ \\
\hline \multirow[t]{6}{*}{ RNA } & Moderna / NIAID & LNP-encapsulated mRNA & Advantages \\
\hline & $\begin{array}{l}\text { BioNTech/ Fosun } \\
\text { Pharma/ Pfizer }\end{array}$ & 3 LNP-mRNAs & $\begin{array}{l}\text { More flexibility in preventing } \\
\text { or treating rapidly evolving }\end{array}$ \\
\hline & Curevac & m RNA & pathogens. \\
\hline & Arcturus/ Duke - NUS & mRNA & Disadvantages \\
\hline & Imperial College London & LNP - nCoVsaRNA & Vaccines that are mRNA-based \\
\hline & $\begin{array}{l}\text { Walvax Biotech / PLA } \\
\text { Academy of Military } \\
\text { Sciences }\end{array}$ & mRNA & $\begin{array}{l}\text { induce type I interferon responses, } \\
\text { associated with inflammation } \\
\text { and autoimmunity. }\end{array}$ \\
\hline \multirow[t]{7}{*}{ DNA } & Inovio Pharmaceuticals & DNA plasmid vaccine & Advantages \\
\hline & / International Vaccine & (electroporation) & - These vaccines have a \\
\hline & Takara Bio / & DNA plasmid vaccine & better stability as compared \\
\hline & $\begin{array}{l}\text { Osaka University/ } \\
\text { AnGes }\end{array}$ & containing Adjuvant & $\begin{array}{l}\text { to traditional vaccines. } \\
\text { - It also has a better control }\end{array}$ \\
\hline & ZyCov-D / Zydus & DNA plasmid vaccine & on vaccine design as the gene \\
\hline & Cadila Healthcare & & $\begin{array}{l}\text { of interest can be added or deleted } \\
\text { Disadvantages }\end{array}$ \\
\hline & Genexine Consortium & DNA Vaccine (GX-19) & $\begin{array}{l}\text { - These vaccines have a high } \\
\text { production cost as compared } \\
\text { to other vaccine types. } \\
\text { - In these DNA vaccines mutations } \\
\text { in host DNA is possible. }\end{array}$ \\
\hline \multirow{7}{*}{$\begin{array}{l}\text { Replicating } \\
\text { Viral Vector }\end{array}$} & Institute Pasteur/Themis/ & Measles - vector based & Advantages \\
\hline & $\begin{array}{l}\text { University of Pittsburg } \\
\text { CVR/ Merck Sharp } \\
\text { and Dohme }\end{array}$ & & $\begin{array}{l}\text { - More persistent immunity due } \\
\text { to continued expression of } \\
\text { inserted genes. }\end{array}$ \\
\hline & Beijing Wantai & Intranasal flu - based - RBD & - Stimulation of co-stimulatory \\
\hline & Biological & & signals and proinflammatory \\
\hline & Pharmacy/ Xiamen & & cytokines \\
\hline & University & & Disadvantages \\
\hline & & & $\begin{array}{l}\text { Prior immunity concern for } \\
\text { intranasal administration. }\end{array}$ \\
\hline
\end{tabular}

having a high risk of developing severe COVID infections. ${ }^{76,77}$ However, another antibody cocktail manufactured by AstraZeneca plc proved to be only $33 \%$ effective in clinical trials, and thus was not further used. ${ }^{78}$

\section{Current Scenario}

Due to the emergency situation of pandemic, new developments in diagnosis, treatment, vaccine development $\&$ their trials are progressing at a very high pace. The research on seeking COVID-19 vaccines started by different countries in early 2020 and within a span period of one year several vaccines got emergency use authorization. Studies based on clinical trials using these vaccines showed a dramatic reduction in COVID-19 infections. Pfizer-BioNTech was the first vaccine to be authorized for emergency use by FDA followed by Moderna vaccine. Vaccination began on December 8, 2020, with healthcare workers and people above 80 were the first to be vaccinated. Shortly after, Bahrain and Canada issued an emergency permission. According to US FDA authorities, four volunteers who received the Pfizer vaccine injections during the study-experienced Bell's palsy, or facial paralysis. Anyone with a history of allergy to any food item or medication was advised not to use PfizerBioNTech. 
On December 29, 2020, the UK Medicines and Healthcare products Regulatory Agency (MHRA) authorized AstraZeneca for immediate use on emergency for individuals of 18 years or above. It shows $63.09 \%$ efficacy towards symptomatic infection in Phase 3 clinical trials. Sputnik V demonstrates $91.6 \%$ efficacy in Phase 3 trials based on the data of 19,866 volunteers in Russia with no adverse symptoms. Evaluating various COVID vaccines, WHO (2021) reported eight vaccines namely Pfizer/BioNTech (BNT162b2), Janssen (Johnson and Johnson Ad26.COV2.S), Moderna (mRNA-1273), AstraZeneca/Oxford (AZD1222), Sinopharm (BBIBP-CorV), Sinovac (CoronaVac), Covishield and Covaxin safe and effective and give EUL status. ${ }^{79}$ Few vaccines are recommended for use in children above 5 years of age. $^{80}$

Recent reports state that there are 28 COVID vaccines that have been approved at least by one country and used as a preventive or control measure all over the world. There are certain candidates in clinical trials as well. At a global scale, 135 vaccine candidates are undergoing clinical trials, while 194 are in pre-clinical development. ${ }^{81}$

In India, COVID-19 vaccines from Serum Institute - Covishelid and Bharat Biotech - Covaxin were launched on $16^{\text {th }}$ January 2021. About three crore healthcare workers and frontline warriors were prioritized, followed by the second group consisting of individuals above the age of 60 . The two vaccines obtained EUL status from WHO on $16^{\text {th }}$ February and $3^{\text {rd }}$ November 2021 respectively. Other vaccines approved for use in India include Janssen (Johnson \& Johnson), Moderna, Sputnik V, ZyCoV-D (Zydus Cadila), AZD1222, COVOVAX and BECOV2D. Over 125 crore COVID vaccine doses have been administered in India so far..$^{82}$ As for the world, more than 56.6 percent global population has received a dose of a COVID-19 vaccine. ${ }^{83}$

SARS-CoV-2 virus is continuously accumulating mutations and changing its genome with time that impacts its transmissibility, virulence and severity of the associated disease. Since January 2020, alpha, beta, gamma, delta and recently omicron variants have been isolated that may affect the vaccine performance. Boosters/ third dose are suggested if adequate immunity is not achieved on vaccination or immunity wane with time or if immunity is less effective against emerging variants. More than 277 million (3.6\%) booster doses have been administered worldwide by many countries, the others may follow it soon ${ }^{83}$ The feasibility of developing pan corona vaccines to manage such pandemics in near future is also being investigated that can provide a wider range of immunity to different corona viruses. ${ }^{84}$

All the potential vaccine candidates have been summarized in Table 2 .

\section{CONCLUSION}

Mass vaccination worldwide against the SARS-CoV-2 virus at a rapid pace is the key approach to control COVID-19 pandemic. Since January 2020, great efforts are made by scientists on a global level to develop effective vaccines using different platforms and at present 28 vaccines are approved at least by one country. More than 300 candidate vaccines are in the pre-clinical stage or undergoing in clinical trials; many of which are front-runners. Most of the vaccines fall in the category of Non-Replicating Viral Vectors, Inactivated Vaccines, mRNA-based Vaccines, Virus-like Particles, DNA Plasmid Vaccines, Protein Subunit Vaccines, Receptor Binding Domain-based Vaccines, Naked DNA based Vaccines, Attenuated SARS-CoV-2 Virus Vaccines or Replicating Viral Vector Vaccines. All of them have their associated benefits and limitations, and thus a vaccine candidate is only approved after it passes through a rigorous multi-phase clinical trial and is found to be effective and safe. The ideal vaccine should be safe, inexpensive, able to generate strong \& long-term immunity and be effective with the emerging new variants of CoV-2. Eight vaccines namely, Pfizer-BioNTech, Moderna, Janssen, AstraZeneca/Oxford, Sinopharm, Sinovac, Covishield and COVAXIN have given EUL status by WHO. Till November 2021, more than $50 \%$ of the global population have been vaccinated. However, fast evolution in coronaviruses resulted in various variants that differ in transmissibility, infection severity and vaccine efficacy thus demanding search for new vaccines. Moreover, inadequate immunity or fading of immune response with time demands for the additional dose in fully vaccinated individuals and around $3.6 \%$ of the world's population has received boosters in many 
countries. The scientists are also working on developing pan corona vaccines to manage such pandemics in near future.

\section{ACKNOWLEDGMENTS}

The authors would like to thank their respective Universities, Institutions and Star College Scheme of Department of Biotechnology for their support.

\section{CONFLICT OF INTEREST}

The authors declare that there is no conflict of interest.

\section{AUTHORS' CONTRIBUTION}

$A, A J, P S$ and RC collection of literature review sources and designed the tables and figures. NN and SA did the conceptualization and designing. AS, SA, SS and NN drafted the manuscript. SA and SS approved the final manuscript for publication.

\section{FUNDING}

None.

\section{DATA AVAILABILITY}

All datasets generated or analyzed during this study are included in the manuscript.

\section{ETHICS STATEMENT}

Not Applicable.

\section{REFERENCES}

1. Mehta P, McAuley D, Brown M, Sanchez E, Tattersall R, Manson J. COVID-19: consider cytokine storm syndromes and immunosuppression. The Lancet. 2020;395(10229):1033-1034. doi: 10.1016/S01406736(20)30628-0

2. Huang $Y$, Yang $C, X u X, X u$ W, Liu S. Structural and functional properties of SARS-CoV-2 spike protein: potential antivirus drug development for COVID-19. Acta Pharmacol Sin. 2020;41(9):1141-1149. doi: 10.1038/s41401-020-0485-4

3. Spinelli A, Pellino G. COVID-19 pandemic: perspectives on an unfolding crisis. British Journal of Surgery. 2020;107(7):785-787. doi: 10.1002/bjs.11627

4. Liu Y, Gayle A, Wilder-Smith A, Rocklov J. The reproductive number of COVID-19 is higher compared to SARS coronavirus. J Travel Med. 2020;27(2):1-4. doi: 10.1093/jtm/taaa021

5. Thanh Le T, Andreadakis Z, Kumar A, et al. The COVID-19 vaccine development landscape. Nat Rev Drug Discov. 2020;19(5):305-306. doi: 10.1038/ d41573-020-00073-5

6. Jeyanathan M, Afkhami S, Smaill F, Miller M, Lichty B,
Xing Z. Immunological considerations for COVID-19 vaccine strategies. Nat Rev Immunol. 2020;20(10):615632. doi: 10.1038/s41577-020-00434-6

7. Ahmed S, Quadeer A, McKay M. Preliminary Identification of Potential Vaccine Targets for the COVID-19 Coronavirus (SARS-CoV-2) Based on SARSCoV Immunological Studies. Viruses. 2020;12(3):254. doi: $10.3390 /$ v12030254

8. Fontanet A, Cauchemez S. COVID-19 herd immunity: where are we? Nat Rev Immunol. 2020;20(10):583584. doi: 10.1038/s41577-020-00451-5

9. Yamey G, Schaferhoff $M$, Hatchett $R$, Pate $M$, Zhao F, McDade K. Ensuring global access to COVID-19 vaccines. The Lancet. 2020;395(10234):1405-1406. doi: 10.1016/S0140-6736(20)30763-7

10. Boopathi S, Poma A, Kolandaivel P. Novel 2019 coronavirus structure, mechanism of action, antiviral drug promises and rule out against its treatment. J Biomol Struct Dyn. 2021;39(9):3409-3418. doi: 10.1080/07391102.2020.1758788

11. COVID-19 Tracker. https://www.bloomberg.com/ graphics/covid-vaccine-tracker-global-distribution/ (Accessed January 31, 2022)

12. Jeskowiak I, Wiatrak B, Grosman-Dziewiszek P, Szelag A. The Incidence and Severity of Post-Vaccination Reactions after Vaccination against COVID-19. Vaccines. 2021;9(5):502. doi: 10.3390/vaccines9050502

13. Walls A, Park Y, Tortorici M, Wall A, McGuire A, Veesler D. Structure, Function, and Antigenicity of the SARSCoV-2 Spike Glycoprotein. Cell. 2020;181(2):281-292. doi: 10.1016/j.cell.2020.02.058

14. Wong $\mathrm{Y}$, Lau S, Wang To K, et al. Natural Transmission of Bat-like Severe Acute Respiratory Syndrome Coronavirus 2 Without Proline-Arginine-ArginineAlanine Variants in Coronavirus Disease 2019 Patients. Clin Infect Dis. 2021;73(2):e437-e444. doi: 10.1093/ cid/ciaa953

15. Li G, Hu R, Zhang X. Antihypertensive treatment with ACEI/ARB of patients with COVID-19 complicated by hypertension. Hypertens Res. 2020;43(6):588-590. doi: 10.1038/s41440-020-0433-1

16. Rivellese F, Prediletto E. ACE2 at the centre of COVID-19 from paucisymptomatic infections to severe pneumonia. Autoimmun Rev. 2020;19(6):102536. doi: 10.1016/j.autrev.2020.102536

17. Robert-Guroff M. Replicating and non-replicating viral vectors for vaccine development. Curr Opin Biotechnol. 2007;18(6):546-556. doi: 10.1016/j. copbio.2007.10.010

18. Van Riel D, de Wit E. Next-generation vaccine platforms for COVID-19. Nat Mater. 2020;19(8):810-812. doi: 10.1038/s41563-020-0746-0

19. Ye T, Zhong Z, Garcia Sastre A, Schotsaert M, De Geest B. Current Status of COVID-19 (Pre) Clinical Vaccine Development. Angew Chem Int Edit. 2020;59(43):18885-18897. doi: 10.1002/ anie. 202008319

20. Feng $\mathrm{L}$, Wang $\mathrm{Q}$, Shan $\mathrm{C}$, et al. An adenovirus-vectored COVID-19 vaccine confers protection from SARSCOV-2 challenge in rhesus macaques. Nat Commun. 2020;11(1):4207 doi: 10.1038/s41467-020-18077-5 
Competent Vesicular Stomatitis Virus Vaccine Vector Protects against SARS-CoV-2-Mediated Pathogenesis in Mice. Cell Host Microbe. 2020;28(3):465-474. doi: 10.1016/j.chom.2020.07.018

22. Logunov DY, Dolzhikova IV, Zubkova OV, et al. Safety and immunogenicity of an rAd26 and rAd5 vector-based heterologous prime-boost COVID-19 vaccine in two formulations: two open, non-randomised phase $1 / 2$ studies from Russia. The Lancet. 2020;396(10255):887897. doi: 10.1016/s0140-6736(20)31866-3

23. Bar-Zeev N, Inglesby T. COVID-19 vaccines: early success and remaining challenges. The Lancet. 2020;396(10255):868-869. doi: 10.1016/s01406736(20)31867-5

24. Yliharsila M, Harju E, Arppe R, et al. Genotyping of clinically relevant human adenoviruses by array-in-well hybridization assay. Clin Microbiol Infect. 2013;19(6):551-557. doi: 10.1111/j.14690691.2012.03926.x

25. Cimolai N. Preliminary concerns with vaccine vectors. Mutagenesis. 2020;35(4):359-360. doi: 10.1093/ mutage/geaa020

26. Cohen J. Vaccine designers take first shots at COVID-19. Science.2020;368(6486):14-16. doi: 10.1126/science.368.6486.14

27. Mangi F, Lyu D, Dilawar I. China's CanSino Covid Vaccine Shows $65.7 \%$ Efficacy. Bloomberg News. 2021. https:// www.bloomberg.com/news/articles/2021-02-08/ pakistan-says-cansino-s-covid-vaccine-shows-65-7efficacy. Accessed March 26, 2021.

28. Petersen E, Wejse C, Zumla A. Advancing COVID-19 vaccines - avoiding different regulatory standards for different vaccines and need for open and transparent data sharing. Int J Infect Dis.. 2020;98:501-502. doi: 10.1016/j.ijid.2020.08.043

29. Mahase E. Covid-19: Oxford researchers halt vaccine trial while adverse reaction is investigated. BMJ. 2020;370:m3525. doi: 10.1136/bmj.m3525. PMID: 32907856

30. The Oxford/AstraZeneca COVID-19 vaccine: what you need to know. 2021. https://www.who.int/newsroom/feature-stories/detail/the-oxford-astrazenecacovid-19-vaccine-what-you-need-to-know. Accessed March 25, 2021.

31. Saha R, Sharma A, Singh M, et al. Repurposing Drugs, Ongoing Vaccine, and New Therapeutic Development Initiatives Against COVID-19. Front Pharmacol. 2020;11:1258. doi: 10.3389/fphar.2020.01258

32. Gao Q, Bao L, Mao H, et al. Development of an inactivated vaccine candidate for SARS-CoV-2. Science. 2020;369(6499):77-81. doi: 10.1126/science.abc1932

33. Varghese PM, Tsolaki AG, Yasmin H, et al. Hostpathogen interaction in COVID-19: Pathogenesis, potential therapeutics and vaccination strategies. J Immunol. 2020;225(6):152008. doi: 10.1016/j. imbio.2020.152008

34. Kandimalla R, John A, Abburi C, Vallamkondu J, Reddy P. Current Status of Multiple Drug Molecules, and Vaccines: An Update in SARS-CoV-2 Therapeutics. Mol Neurobiol. 2020;57(10):4106-4116. doi: 10.1007/ s12035-020-02022-0

35. Zhang $\mathrm{Y}$, Zeng $\mathrm{G}$, Pan $\mathrm{H}$, et al. Safety, tolerability, and immunogenicity of an inactivated SARS-CoV-2 vaccine in healthy adults aged 18-59 years: a randomised, double-blind, placebo-controlled, phase $1 / 2$ clinical trial. The Lancet Infect Dis. 2021;21(2):181-192. doi: 10.1016/s1473-3099(20)30843-4

36. Isakova-Sivak I, Rudenko L. A promising inactivated whole-virion SARS-CoV-2 vaccine. The Lancet Infect Dis. 2021;21(1):2-3. doi: 10.1016/s1473-3099(20)30832-x

37. Ragan I, Hartson L, Dutt $T$, et al. A whole virion vaccine for COVID-19 produced via a novel inactivation method: results from animal challenge model studies. BioRxiv. 2020. doi: 10.1101/2020.11.13.381335

38. Chugh T. Timelines of COVID-19 Vaccines. Curr Med Res Pract. 2020;10(4):137-138. doi: 10.1016/j. cmrp.2020.07.009

39. Covishield and Covaxin against Covid-19: All you need to know about the vaccines. 2021. https://www. livemint.com/science/health/covishield-and-covaxinagainst-covid-19-all-you-need-to-know-about-thevaccines-11609737696608.html. Accessed March 25, 2021.

40. Zhang $\mathrm{N}$, Li $\mathrm{X}$, Deng $\mathrm{Y}$, et al. A Thermostable mRNA Vaccine against COVID-19. Cell. 2020;182(5):12711283.e16. doi: 10.1016/j.cell.2020.07.024

41. Mulligan M, Lyke K, Kitchin N, et al. Phase I/II study of COVID-19 RNA vaccine BNT162b1 in adults. Nature. 2020;586(7830):589-593. doi: 10.1038/s41586-0202639-4

42. Sumirtanurdin R, Barliana M. Coronavirus Disease 2019 Vaccine Development: An Overview. Viral Immunol. 2021;34(3):134-144. doi: 10.1089/vim.2020.0119

43. CureVac's COVID-19 vaccine begins rolling review with EMA. Pharma Times. 2021. https://www. pharmatimes.com/news/curevacs_covid-19_vaccine_ begins_rolling_review_with_ema_1363316 (15 February, 2021)

44. McKay PF, Hu K, Blakney AK, et al. Self-amplifying RNA SARS-CoV-2 lipid nanoparticle vaccine candidate induces high neutralizing antibody titers in mice. Nat Commun. 2020;11(1):3523. doi: 10.1038/s41467-02017409-9

45. Rosales-Mendoza S, Marquez-Escobar V, GonzalezOrtega O, Nieto-Gomez R, Arevalo-Villalobos J. What Does Plant-Based Vaccine Technology Offer to the Fight against COVID-19?. Vaccines. 2020;8(2):183. doi: 10.3390/vaccines 8020183

46. Ghorbani A, Zare F, Sazegari S, Afsharifar A, Eskandari $M$, Pormohammad A. Development of a novel platform of virus-like particle (VLP)-based vaccine against COVID-19 by exposing epitopes: an immunoinformatics approach. New Microbes New Infect. 2020;38:100786. doi: 10.1016/j.nmni.2020.100786

47. Yatoo MI, Hamid Z, Parray OR, et al. COVID-19 - Recent advancements in identifying novel vaccine candidates and current status of upcoming SARS-CoV-2 vaccines. Hum Vaccin Immunother. 2020;16(12):2891-2904. doi: 10.1080/21645515.2020.1788310

48. Tatlow D, Tatlow C, Tatlow S, Tatlow S. A novel concept for treatment and vaccination against Covid-19 with an inhaled chitosan-coated DNA vaccine encoding a secreted spike protein portion. Clin Exp Pharmacol Physiol. 2020;47(11):1874-1878. doi: 10.1111/1440- 


\subsection{3}

49. Smith T, Patel A, Ramos S, et al. Immunogenicity of a DNA vaccine candidate for COVID-19. Nat Commun 2020;11(1):2601. doi: 10.1038/s41467-020-16505-0

50. Betsaida BA, Laguipo B. Advancements in DNA vaccines against COVID-19. News-Medical.net. 2021. https://www.news-medical.net/news/20210217/ Advancements-in-DNA-vaccines-against-COVID-19. aspx. Accessed March 25, 2021.

51. Solano JJ, Maki DG, Adirim TA, Shih RD, Hennekens $\mathrm{CH}$. Public health strategies contain and mitigate COVID-19: A tale of two democracies. Am J Med. 2020;133(12):1365-1366. https://dx.doi. org/10.1016\%2Fj.amjmed.2020.08.001

52. Kalita P, Padhi AK, Zhang KYJ, Tripathi T. Design of a peptide-based subunit vaccine against novel coronavirus SARS-CoV-2. Microb Pathog. 2020;145:104236. doi: 10.1016/j.micpath.2020.104236

53. Kumar N, Sood D, Chandra R. Design and optimization of a subunit vaccine targeting COVID-19 molecular shreds using an immunoinformatics framework. RSC Adv. 2020;10(59):35856-35872. doi: 10.1039/ DORA06849G

54. Qamar MT, Shahid F, Aslam S, et al. Reverse vaccinology assisted designing of multiepitope-based subunit vaccine against SARS-CoV-2. Infect Dis Poverty. 2020;9(1):132. doi: 10.1186/s40249-020-00752-w

55. Begum J, Mir N, Dev K, Buyamayum B, Wani M, Raza $M$. Challenges and prospects of COVID-19 vaccine development based on the progress made in SARS and MERS vaccine development. Transbound Emerg Dis. 2020;68(3):1111-1124. doi: 10.1111/tbed.13804

56. Funk C, Laferriere C, Ardakani A. A Snapshot of the Global Race for Vaccines Targeting SARS-CoV-2 and the COVID-19 Pandemic. Front Pharmacol. 2020;11:937. doi: 10.3389/fphar.2020.00937

57. Tai $W$, Zhang $X$, Drelich A, et al. A novel receptorbinding domain (RBD)-based mRNA vaccine against SARS-CoV-2. Cell Res. 2020;30(10):932-935. doi: 10.1038/s41422-020-0387-5

58. Makoni M. COVID-19 vaccine trials in Africa. Lancet Respir Med. 2020;8(11):e79-e80. doi: 10.1016/s22132600(20)30401-x

59. Raja A, Alshamsan A, Al-jedai A. Current COVID-19 vaccine candidates: Implications in the Saudi population. Saudi Pharm J. 2020;28(12):1743-1748. doi: 10.1016/j.jsps.2020.10.019

60. Le TT, Cramer JP, Chen R, Mayhew S. Evolution of the COVID-19 vaccine development landscape. Nat Rev Drug Discov. 2020;19(10):667-668. doi: 10.1038/ d41573-020-00151-8

61. Fidel P, Noverr M. Could an Unrelated Live Attenuated Vaccine Serve as a Preventive Measure To Dampen Septic Inflammation Associated with COVID-19 Infection?. mBio. 2020;11(3):E00907-20. doi: 10.1128/ mbio.00907-20

62. Mukherjee R. Global efforts on vaccines for COVID-19: Since, sooner or later, we all will catch the coronavirus. J Biosci. 2020;45(1):68. doi: 10.1007/s12038-02000040-7

63. Arashkia A, Jalilvand S, Mohajel N, et al. Severe acute respiratory syndrome-coronavirus-2 spike (S) protein based vaccine candidates: State of the art and future prospects. Rev Med Virol. 2021;31(3):E2183. doi: 10.1002/rmv.2183

64. Kochhar S, Salmon D. Planning for COVID-19 vaccines safety surveillance. Vaccine. 2020;38(40):6194-6198. doi: 10.1016/j.vaccine.2020.07.013

65. Jain S, Batra H, Yadav P, Chand S. COVID-19 Vaccines Currently under Preclinical and Clinical Studies, and Associated Antiviral Immune Response. Vaccines. 2020;8(4):649. doi: 10.3390/vaccines8040649

66. Pandey A, Singh N, Mittal SK. Egg-independent vaccine strategies for highly pathogenic H5N1 influenza viruses. Hum Vaccin. 2010;6(2):178-88. doi: 10.4161/ hv.6.2.9899

67. Kurup VM, Thomas J. Edible vaccines: promises and challenges. Mol Biotechnol. 2020;62(2):79-90. doi: 10.1007/s12033-019-00222-1

68. Zheng N, Xia R, Yang $\mathrm{C}$, et al. Boosted expression of the SARS-CoV nucleocapsid protein in tobacco and its immunogenicity in mice. Vaccine. 2009;27(36):50015007. doi: 10.1016/j.vaccine.2009.05.073

69. Capell T, Twyman RM, Armario-Najera V, Ma JK, Schillberg S, Christou P. Potential applications of plant biotechnology against SARS-CoV-2. Trends Plant Sci. 2020;25(7):635-643. doi: 10.1016/j. tplants.2020.04.009

70. Phillip Morris International . Medicago develops a plant-based vaccine for Coronavirus. 2020. https:// www.pmi.com/media-center/news/medicagodevelops-a-plant-based-vaccine-for-coronavirus ( Accessed 19 march 2020)

71. iBio. iBio announces development of proprietary COVID-19 vaccine candidates. 2020. https://www.globenewswire.com/newsrelease/2020/03/18/2002546/0/en/iBio-AnnouncesDevelopment-of-Proprietary-COVID-19-VaccineCandidates.html ( Accessed 18 March 2020)

72. ISAAA. Native australian plant paves way for vaccine development against COVID-19. 2020. https://www. isaaa.org/kc/cropbiotechupdate/article/default. asp?ID=18054 (Accessed 8 April 2020)

73. ISAAA . Nanoengineers combine molecular farming and advanced manufacturing to develop COVID-19 vaccine. 2020. https://www.isaaa.org/kc/cropbiotechupdate/ article/default.asp?ID=18090 ( Accessed 29 April 2020)

74. WHO. DRAFT landscape of COVID-19 candidate vaccines - 18 June 2020. 2020. https://www.who.int/ docs/default-source/coronaviruse/novel-coronaviruslandscape-covid-194eb79ebd8d044863b4d4bcedbb1 4a3ce.pdf (Accessed 29 June 2020)

75. Dhama K, Natesan S, Yatoo I, et al, H. Plant-based vaccines and antibodies to combat COVID-19: current status and prospects. Human Vaccines \& Immunotherapeutics, 2020;16(12), 2913-2920. doi: 10.1080/21645515.2020.1842034

76. Business Today. 2021. https://www.businesstoday. in/coronavirus/story/roche-covid-19-antibodycocktail-launched-in-india-at-rs-59750-perdose-296890-2021-05-24 (Accessed 19 Jan 2022)

77. The Times of India. 2021. https://timesofindia. indiatimes.com/india/how-low-cost-antibodycocktail-can-be-game-changer-in-indias-covid-fight/ 
articleshow/83089132.cms ( Accessed May 30 2021)

78 Business Standard. 2021. https://www.reuters.com/ business/healthcare-pharmaceuticals/astrazenecasays-its-antibody-treatment-failed-in-preventingcovid-19-exposed-2021-06-15/ ( Accessed June 15 2021)

79. WHO. 2021. https://www.who.int/emergencies/ diseases/novel-coronavirus-2019/covid-19-vaccines

80. CDC. Different COVID-19 Vaccines. 2021. https://www. cdc.gov/coronavirus/2019-ncov/vaccines/differentvaccines.html
81. WHO. COVID-19 vaccine tracker and landscape. 2021. https://www.who.int/publications/m/item/draftlandscape-of-covid-19-candidate-vaccines

82. Co-WIN. 2021. https://www.cowin.gov.in/

83. Tracking coronavirus vaccinations around the world. 2021. https://www.nytimes.com/interactive/2021/ world/covid-vaccinations-tracker.html

84. Kwon Diana. The Quest for a Universal Coronavirus Vaccine. The Scientists 2021. https://www.thescientist.com/news-opinion/the-quest-for-a-universalcoronavirus-vaccine-68934 (Accessed June 29 2021) 